believe that 8-quinolinol sulphate does not possess eytokinin-like activity.

Department of Floriculture

A. Rameshwar

Peter L. Steponkes

and Ornamental Horticulture,

Cornell University,

Ithaca, Now York.

Received April 20, 1970.

${ }^{1}$ Chua, S. E., Nature, 225, 101 (1970).

'Miiller, C. O.. Proc. US X̃at. Acad. Sci., 54, 1052 (1965).

\section{Development of Dormancy during Seed Maturation in Avena ludoviciana Winter Wild Oat}

STUDIES on seed dormancy have concentrated on the physiology of dormancy break in mature seeds rather than its development during maturation. Thurston ${ }^{1}$ reported that unripe grains of Avena ludoviciana did not exhibit substantial dormaney, and Quail and Carter ${ }^{2}$ demonstrated the same phenomenon in Australian material of this species. We have confirmed these findings and have concluded that the development of dormancy is influenced both by the parent plant and by events independent of the parent.

The seed of A. ludoviciana is a caryopsis surrounded by hard hulls or pales. Normally the spikelet comprises two such seeds and it does not disarticulate at maturity. This foature in contrast to $A$. fatua, the spring wild oat, makes it possible to compare directly seeds from the same spikelet. Such a comparison shows that there is a gradient of dormancy within the spikelet, the larger proximal seed being less dormant than the smaller distal seed ${ }^{1,2}$, while a much smaller third secd, occasionally present, is extremely dormant ${ }^{3}$.

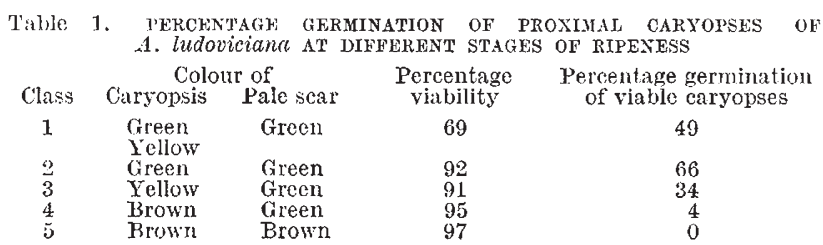

A. ludoviciana was grown outdoors in a good soil. Spikelets were collected at intervals and scored for ripeness judged on the colour of the caryopis and the pale scar. Five classes of ripeness were recognized, as indicated in Table 1. At harvest, the pales were removed by hand and the caryopses were set to germinate at $10^{\circ} \mathrm{C}$ in darkness. Twenty caryopses and $1.5 \mathrm{ml}$. of distilled water were placed in $4.5 \mathrm{~cm}$ Petri dishes lined with Whatman seed test paper. There were five replicates per treatment. Germination was scored after 14 days and caryopses which had not germinated by then were pricked with a needle just above the scutellum to break dormancy. Subsequent germination indicated the seeds' viability. Where appropriate a $\chi^{2}$ comparison was carried out.

Table I indicates that, as shown previously ${ }^{1,2}$, dormancy develops during seed maturation. Futhermore, this dormancy resides in the caryopsis itself and does not result from maturatiom of the pales, a process which is known to inhibit germination in non-dormant caryopses ${ }^{3}$. Viability is low in very young caryopses but rapidly reaches levels found in mature material. At maturity all caryopses are dormant, even at $10^{\circ} \mathrm{C}$, the optimum temperaturo for germination ${ }^{2,3}$.

Because loss of water is an integral part of seed ripening, the development of dormancy was studied in dried immature seed. Seed belonging to classes 2 and 4 was
Table 2. PERCENTAGE GERMINATION OF DRIED AND UNDRIED IMMATURE CARYOPSES OF $\boldsymbol{A}$. ludoriciana

\begin{tabular}{|c|c|c|c|c|c|c|}
\hline \multirow[b]{2}{*}{ Class } & \multicolumn{3}{|c|}{ Proximal caryonses } & \multicolumn{3}{|c|}{ Distal caryonses } \\
\hline & Not dried & Dried & $x^{2}$ & Not dried & Dried & $x^{2}$ \\
\hline$\stackrel{2}{4}^{4}$ & $\begin{array}{l}44 \\
16 \\
+P_{0.05}\end{array}$ & $\begin{array}{r}12 \\
6\end{array}$ & $\begin{array}{c}23 \cdot 83^{*} \\
4 \cdot 13 \dagger\end{array}$ & 31 & $\begin{array}{l}4 \\
1\end{array}$ & $\begin{array}{r}23.41^{*} \\
4.18 \dagger\end{array}$ \\
\hline
\end{tabular}

harvested and dried for 6 days at room temperature before germination was assessed as previously described. Drying increased the level of dormancy in such samples (Table 2), indicating that after a certain stage, dormancy can develop in a seed separated from the parent plant.

The inception of dormancy usually takes place on the parent plant. Thurston ${ }^{4}$ has shown that removal of the proximal ovary decreases dormancy in the distal seed. Natural loss of a seed in a spikelet also decreases dormancy in the survivor, although the phenomenon is more marked when the distal seed is the survivor (Table 3). A plausible explanation for the decline in dormancy is that, during ripening, both seeds act as sinks for a limited supply of some promotive substance. Being larger and perhaps nearer the source, the proximal seed normally receives more promoter than the distal, and thus removal of the proximal has a greater effect on the surviving distal seed than the opposite case.

Table 3. PERCENTAGE GERMINATION OF SEEDS WHICH DEVELOPED AIONE

$$
\begin{array}{lccc}
\multicolumn{1}{c}{\text { Seed type }} & \multicolumn{2}{c}{\text { Proximal }} & \multicolumn{2}{c}{\text { Distal }} \\
\text { Neighbour } & \text { Present Absent } & \text { Present A } \\
\text { Germination } & 67 & 27 & 27 \\
\chi^{2} \text { Presence vs. absence } & \multicolumn{2}{c}{4 \cdot 39^{*}} & \multicolumn{2}{c}{276^{*}}
\end{array}
$$$$
\text { OR WITH NEIGIBOURS }
$$

Present
67 $\stackrel{\text { Absent }}{81} \quad \begin{gathered}\text { Present } \\ 27\end{gathered}$

Table 4. PERCENTAGE GEIMINATION OF PROXIMAL CARYOPSES FROM PANICLES E GERMINATION OF PROXIMAL CART
RITENED IN VARYOUS SOLUTIONS

\begin{tabular}{lccccc} 
& \multicolumn{2}{c}{ Concentration } & \multicolumn{2}{c}{$*^{2}$ Treatment rs. water } \\
Treatment & $10^{-4} \mathrm{M}$ & $10^{-3} \mathrm{M}$ & $10^{-4} \mathrm{M}$ & $10^{-3} \mathrm{M}$ \\
Gibberellic acid & 43 & 100 & $14 \cdot 24^{*}$ & $110 \cdot 22^{*}$ \\
Coumarin & & 36 & & $8 \cdot 52^{*}$ \\
PCMB & 42 & 83 & $13 \cdot 49^{*}$ & $66 \cdot 64^{*}$ \\
Iodoacetate & 12 & \multirow{2}{*}{14} & 95 & $0 \cdot 00$ & $98 \cdot 87^{*}$ \\
Water & & & &
\end{tabular}

* $P 0.01 . \dagger P 0.05$.

Black and Naylor ${ }^{5}$ have already demonstrated that the introduction of a promotive substance, gibberellic acid, to ripening seed of $A$. fatua renders them non-dormant. In a similar experiment, detached panicles of $A$. ludoviciana were ripened in a glasshouse in solutions of gibberellic acid with similar results (Table 4). Furthermore, it has been shown that the metabolic inhibitors sodium $p$. chloromercuribenzoate, sodium iodoacetate and coumarin will sharply reduce the development of dormancy in ripening seeds of this species. The latter result is interesting because whereas gibberellic acid promotes germination in this species, $p$-chloromercuribenzoate and iodoacetate have no effect at the concentrations quoted, and coumarin causes some inhibition ${ }^{3}$. It is not known whether the site of action of these substances during ripening is in the parent plant or in the developing seed.

We propose that dormancy seeds of $A$. ludoviciana depends partly on (a) a supply of a promotive substance which is shared among the seeds present and $(b)$ a process occurring in the caryopsis during ripening, whether attached to the parent plant or not. Furthermore, it secms that a detailed investigation of the effects of the inhibitors we have mentioned may help to explain the inception of dormancy during seed ripening.

S. F. Morgan

Department of Botany,

A. M. M. BerRIE

The University,

Glasgow W2.

Reccived July 13, 1970.

I Thurston, J. M., Proc. First Brit. Weed Control Conf., 240 (1953).

2 Quail, P. H. and Carter, O. G, A ustral. J. Agric. Res., 20, 1 (1969).

${ }^{3}$ Morgan, S. F., thesis, Univ. Glasgow (1968).

4 Thurston, .T. M., The Biology of Weeds (edit. by Harper, J. L.) (Blackwell, Oxford, 1960).

5 Black, M., and Naylor, J. M., Nature, 184, 468 (1959). 